\title{
Evaluation of the efficacy of filling material removal and re-filling after different retreatment procedures
}

Roberta Fonseca de CASTRO(a) Juliana do Socorro Soares MELO(a) Luiz Carlos de Lima DIAS JUNIOR(a) Emmanuel João Nogueira Leal SILVA ${ }^{(b)}$ Juliana Melo da Silva BRANDÃO(a)

(a) Universidade Federal do Pará - UFPA, Department of Endodontics, Belém, PA, Brazil.

(b) Universidade do Grande Rio - Unigranrio, Department of Endodontics, Rio de Janeiro, RJ, Brazil.

Declaration of Interests: The authors certify that they have no commercial or associative interest that represents a conflict of interest in connection with the manuscript.

Corresponding Author:

Emmanuel João Nogueira Leal Silva

E-mail: nogueiraemmanuel@hotmail.com

Submitted: February 10, 2018

Accepted for publication: June 27, 2018

Last revision: July 25, 2018
Abstract: This study analyzed the influence of different retreatment protocols on amount of remaining filling material and amount of new sealer after endodontic retreatment. Forty mandibular molars with curved mesial roots were prepared with ProTaper Universal system, and filled with $\mathrm{AH}$ Plus sealer mixed with $0.1 \%$ rhodamine $\mathrm{B}$ and gutta-percha. After 7 days, the specimens were randomized according to the retreatment protocol $(\mathrm{n}=10)$ : ProTaper Retreatment System (PTR); PTR+Orange Oil (PTR+OO); PTR+Passive Ultrasonic Irrigation (PTR+PUI). No retreatment was performed in the control group (CG). After retreatment, the root canals were filled with $\mathrm{AH}$ Plus mixed with $0.1 \%$ fluorescein and gutta-percha. Samples were evaluated under confocal laser scanning microscopy and analyzed using Image J software. Data were analyzed using Kruskal-Wallis and Dunn tests $(\mathrm{p}<0.05)$. Regarding presence of residual filling, the Kruskal-Wallis test indicated no differences among the different retreatment techniques in the perimeter and the isthmus analyses $(p>0.05)$; however, PTR+PUI was associated with a lesser amount of residual filling material in the canal area analysis $(p<0.05)$. In evaluating the new filling, the perimeter analysis showed a lesser amount of new endodontic sealer in the PTR group $(p<0.05)$. Moreover, the PTR+PUI group presented a significantly greater amount of new endodontic sealer in the canal area analysis $(p<0.05)$. There was no difference among groups in the isthmus analysis $(p>0.05)$. It can be concluded that PTR associated to PUI yielded better results in removing root canal filling material from the canal area. However, none of the protocols resulted in root walls completely free of remnants.

Keywords: Endodontics; Microscopy, Confocal; Retreatment; Root Canal Filling Materials.

\section{Introduction}

Root canal retreatment procedures recommend the removal of filling material, because it can cover necrotic material, debris and infected dentine. ${ }^{1,2}$ Different methods have been proposed to remove filling material, such as hand files, rotary systems, and reciprocating instruments with or without ultrasonic inserts and/or solvents. ${ }^{2,3,4,5,6}$ Moreover, the combination of different protocols can make the removal of root canal filling even more effective. ${ }^{1,2}$ 
Numerous analyses have been used in laboratorial studies to assess the remaining filling material, including radiographs, ${ }^{7}$ optical microscope ${ }^{8,9}$ scanning electron microscopy, ${ }_{10}^{10}$ computed tomography ${ }^{11}$ and micro-computed tomography. ${ }^{12,13}$ Preliminary studies have shown the impact of remaining filling in single root canals after various retreatment protocols $\mathrm{s}^{14,15,16}$ using confocal laser scanning microscopy (CLSM) analysis; however, the impact on root canals with greater anatomical complexities, such as mesial mandibular molars, has not yet been clarified.

The mesial root canal of mandibular molars presents not only a high degree of curvature, but also a high incidence of isthmus. ${ }^{17}$ This can make root canal cleaning and disinfection procedures even more difficult. ${ }^{18}$ Anatomical complexities limit the action of instruments, auxiliary chemical substances and medications. Thus, knowledge of anatomical variations and the best retreatment procedures in these situations may improve the endodontic outcomes. ${ }^{19,20}$

The aim of the present study was to evaluate the root canal filling material remaining after root canal retreatment using the ProTaper Retreatment system (Dentsply Maillefer, Ballaigues, Switzerland) with or without ultrasonic inserts or solvents, analyzed using CLSM. The amount of new endodontic sealer after root canal retreatment was also evaluated. The null hypothesis tested was that there are no differences in the amount of remaining root canal filling material or in the amount of new endodontic sealer after using the different endodontic retreatment protocols.

\section{Methodology}

\section{Tooth selection}

This study was approved by the Research Ethics Committee of the Pará Federal University, Belém, Brazil (protocol number 2.041.288).

The sample size was determined after a pilot study indicated that a total of 10 specimen per group would be needed to detect significant differences among the groups. The sample had a test power of $80 \%$ and a significance level of $5 \%$. Forty mesial root canals of mandibular molars were used; they had no visible root caries, fractures, cracks, or any signs of internal and external resorption or calcification, and had a completely formed apex. The root curvature of the selected teeth was between $15^{\circ}$ and $30^{\circ}$, according to Schneider's method. ${ }^{21}$ Preoperative radiographs were taken for each root to confirm the canal anatomy.

\section{Endodontic treatment}

The teeth were decoronated to standardize the roots at $14 \mathrm{~mm}$. Canal patency was checked by passively introducing a size 10 and $15 \mathrm{~K}$-file into each canal until its tip was visible at the apical foramen with a $x 4$ magnifier. The working length (WL) was established $1 \mathrm{~mm}$ short of the major apical foramen.

The canals were prepared with the ProTaper Universal system (Dentsply Maillefer) using SX, S1, S2, F1 and F2 instruments at a speed of $300 \mathrm{rpm}$ and 2 N.cm torque, and driven by an X-Smart electric motor (Dentsply Maillefer). During preparation, $24 \mathrm{~mL}$ of $2.5 \%$ sodium hypochlorite $(\mathrm{NaOCl})$ was delivered to each root canal by disposables syringes and 30-G Endo-Eze needles (Ultradent, South Jordan, UT, USA). Final irrigation was performed with $5 \mathrm{~mL}$ of $17 \%$ EDTA (Biodinâmica, Ibiporã, PR, Brazil) and $3 \mathrm{~mL}$ of saline solution, followed by drying with ProTaper F2 paper points (Dentsply Maillefer).

\section{Root canal filling}

The specimens were filled using AH Plus Sealer (Dentsply Maillefer) and the single-cone obturation technique. During manipulation, the sealer was mixed with $0.1 \%$ rhodamine $\mathrm{B}$, and then carried into the root canal with a \#25 size lentulo spiral (Dentsply Maillefer). An F2 master gutta-percha cone was inserted into the root canal, excess guttapercha was removed using a heated plugger, and the vertical compaction was performed with cold pluggers. The orifices were sealed with temporary restorative material (Coltosol, Vigodent Coltene, RJ, Brasil), and the specimens were stored in $100 \%$ humidity at $37^{\circ} \mathrm{C}$ for seven days.

\section{Endodontic retreatment}

The ProTaper Retreatment system (PTR) (Dentsply Maillefer) was used to remove the filling material in the following sequence: D1, 
D2 and D3, at a speed of $500 \mathrm{rpm}$ for D1, and 400 rpm for D2 and D3 files, with a 4 N.cm torque, and with brushing movements against the walls, as recommended by the manufacturer. In group PTR, only $\mathrm{NaOCl}$ was used during instrumentation. In the PTR + orange oil group (PTR + OO), one drop of the solvent was dispensed into the root canal at each change of instrument. In the PTR + PUI (passive ultrasonic irrigation) group, PUI was performed with an E1 ultrasonic tip (Helse, Santa Rosa de Viterbo, SP, Brazil) set at a low power setting $(10 \%)$ mounted in a piezoelectric ultrasonic device (Enac-Osada, Tokyo, Japan). The ultrasonic tip was placed $2 \mathrm{~mm}$ short of the WL and activated for 20 seconds at each change of instrument. After the removal procedure, the roots were subjected to new instrumentation with ProTaper, up to the F3 file (Dentsply Maillefer). The control group did not receive any retreatment procedures.

The irrigation and root canal filling protocol used during initial endodontic treatment was the same as that used in the retreatment. However, the root canals submitted to retreatment were refilled with AH Plus Sealer mixed with $0.1 \%$ fluorescein, and with a F3 master gutta-percha point. The specimens were stored in $100 \%$ humidity at $37^{\circ} \mathrm{C}$ for seven days.

\section{Specimen preparation and CLSM analysis}

The specimens were sectioned horizontally with a cutting machine (Isomet 1000; Buehler, Lake Forest, IL, USA), under water cooling, at 2, 4 and 6 $\mathrm{mm}$ from the apex. Slices were taken with a CLSM (IX 81 Olympus, Tokyo, Japan) and evaluated using the method of epifluorescence with wavelengths of absorption and emission to rhodamine B of $540 / 590 \mathrm{~nm}$ and to fluorescein of $494 / 518 \mathrm{~nm}$. The samples were analyzed $10 \mu \mathrm{m}$ below the surface sample at 10X magnification.

The CLSM images were combined for further analysis using Adobe Photoshop (Adobe systems incorporated, San Jose, USA), and measured by Image J software (National institutes of health, Bethesda, USA). These images were used to measure:

a. the residual and new filling in the perimeter of the root canal; b. the root canal area with the remaining and the new filling;

c. the isthmus area with the remaining and the new filling.

\section{Statistical analysis}

Each root slice was treated as a statistical unit. The results were analyzed using BioEstat 5.0 software (Instituto Mamirauá, Tefé, Brazil). Shapiro-Wilk tests showed non-normal data distribution. KruskalWallis and Dunn tests were used to detect statistical differences among the groups. A 5\% significance level $(p<0.05)$ was applied for analysis.

\section{Results}

Regarding the presence of residual filling, the Kruskal-Wallis test indicated no differences among the different retreatment techniques in the perimeter and the isthmus analyses ( $p>0.05$ ); however, in the canal area analysis, PTR + PUI was associated with a lower amount of residual filling material than the other groups tested $(p<0.05)$. When the new filling was evaluated, the perimeter analysis showed a lesser amount of the new endodontic sealer in the PTR group $(p<0.05)$. Moreover, the PTR + PUI group presented a significantly greater amount of new endodontic sealer in the canal area analysis, compared with the other groups $(p<0.05)$. There was no difference among the groups in the isthmus analysis $(p>0.05)$ (Figure and Table).

\section{Discussion}

Success in endodontics is achieved through instrumentation, adequate antimicrobial control and a three-dimensional filling of the root canal system. ${ }^{22}$ In the present study, retreatment and refilling analysis was performed by CLSM. Compared with scanning electronic microscopy (SEM), CLSM presents certain advantages, such as a simpler preparation of samples, no need for special specimen processing ${ }^{23}$ and analysis of treatment and retreatment using a single sample. ${ }^{15}$ In addition, the images obtained by CLSM can be evaluated using a quantitative analysis, contrary to evaluation by scores commonly used in 


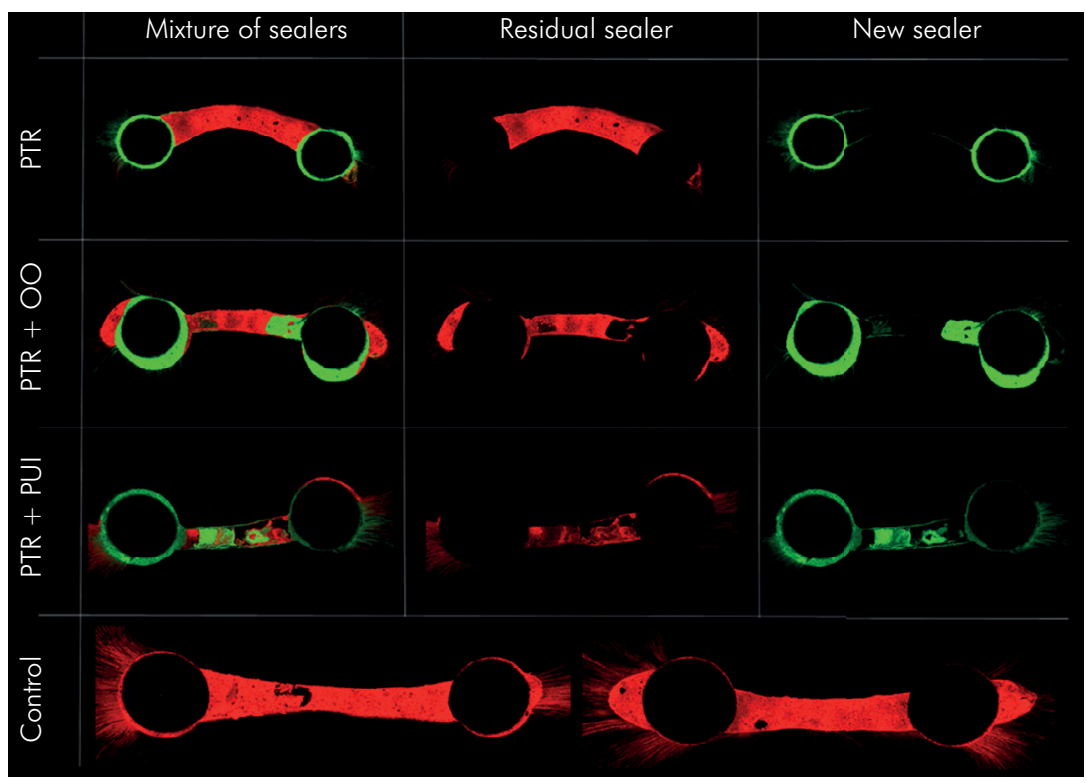

Figure. Representative image of the different groups tested, showing the mixture of sealers, the residual sealer (red), and the new sealer (green), in root canal walls, inside dentinal tubules, and in the isthmus area.

Table. Median, maximum and minimum values of residual and new filling, in percentage, for perimeter, canal area, and isthmus area analysis.

\begin{tabular}{|c|c|c|c|c|c|c|}
\hline \multirow{2}{*}{ Group } & \multicolumn{2}{|c|}{ Perimeter (\%) } & \multicolumn{2}{|c|}{ Canal area (\%) } & \multicolumn{2}{|c|}{ Isthmus area (\%) } \\
\hline & Residual filling & New filling & Residual filling & New filling & Residual filling & New filling \\
\hline \multirow[t]{2}{*}{ PTR } & 58.63 & 45.42 & 41.60 & 71.03 & 79.15 & 22.54 \\
\hline & $(0.0-100)^{A}$ & $(0.0-87.99)^{\mathrm{A}}$ & $(7.74-74.90)^{A}$ & $(29.11-98.42)^{\mathrm{A}}$ & $(10.35-99.79)^{\mathrm{A}}$ & $(0.0-61.71)^{A}$ \\
\hline \multirow[t]{2}{*}{ PTR + OO } & 55.23 & 64.24 & 33.43 & 73.96 & 76.55 & 27.08 \\
\hline & $(25.15-100)^{A}$ & $(10.81-100)^{B}$ & $(10.43-70.21)^{A}$ & $(29.51-93.82)^{\mathrm{A}}$ & $(42.66-100)^{\mathrm{A}}$ & $(0.0-83.21)^{A}$ \\
\hline \multirow[t]{2}{*}{ PTR + PUI } & 46.58 & 63.56 & 18.45 & 83.85 & 76.25 & 29.72 \\
\hline & $(10.58-97.65)^{\mathrm{A}}$ & $(0.0-100)^{\mathrm{B}}$ & $(0.0-40)^{\mathrm{B}}$ & $(60.70-100)^{\mathrm{B}}$ & $(0.0-97.86)^{A}$ & $(0.0-100)^{A}$ \\
\hline
\end{tabular}

Superscript uppercase letters $(A, B)$ indicate a difference among the groups (Kruskal-Wallis and Dunn tests).

SEM analysis. ${ }^{24}$ Rhodamine B and fluorescein dyes were used to contrast the remaining sealer and the new filling sealer after retreatment protocols. When used in low concentrations $(0.1 \%)$, the dyes do not affect the sealer properties. ${ }^{25}$

The mesial roots of mandibular molars were chosen due to their anatomical complexity, especially their high incidence of isthmus. ${ }^{22,26}$ Moreover, the removal of filling material during retreatment is more difficult in curved canals ${ }^{12}$. Thus, the roots included in our study were selected under standardized conditions, with a curvature between $15^{\circ}$ and $30^{\circ}$, determined according to Schneider's method..$^{21}$ The apical third is the area with the greatest anatomical variation, such as accessory canals, isthmus and apical deltas. ${ }^{15}$ The present study used the last $6 \mathrm{~mm}$ of root canal because this portion has the greatest incidence of isthmus in different anatomical variations. ${ }^{20}$ The apical third was divided into three slices of $2 \mathrm{~mm}$ to obtain greater representativeness of this region, thereby including three points of the apical third in the statistical analysis.

Reinstrumentation is necessary after removal of the gutta-percha to promote better cleaning of canal walls. It is performed with larger instruments than those used in initial treatment, whenever possible and secure. ${ }^{27,28}$ However, this enlargement must be carried out carefully to avoid weakening of the 
teeth. In the present study, the instrumentation for the retreatment procedure was performed from $\mathrm{F} 2$ (tip .25) to F3 (tip .30), considering the anatomy and curvature of the selected roots.

The present study showed a greater amount of residual filling in the isthmus area, with percentages similar to those found in the control group ( $p>$ $0.05)$. This indicates that the different protocols tested removed only small amounts of the original root canal filling, a result which also compromised the percentage of new filling in this area. Previous studies using micro-CT analysis have shown that a greater amount of remaining filling is left in the isthmus after endodontic retreatment. This occurs because the isthmus area represents a major challenge for proper cleaning and disinfection, considering that the mechanical instrumentation of this area is unfeasible. ${ }^{29,30}$

None of the protocols yielded root canal walls that were completely free of filling material, a finding corroborated by previously published studies using different methodologies. ${ }^{10,11,14}$ The PTR + PUI technique presented lower values of residual filling in the canal area. Consequently, this technique showed a higher percentage of new filling material in the same area. These results corroborate those of previous studies ${ }^{10,30}$, which showed that PUI produced a significant reduction in residual filling. Ultrasonic activation may promote displacement of filling materials from the root walls, facilitating sealer removal. It is important to emphasize that all the studies mentioned used micro-CT analysis; to the best of the authors' knowledge, this is the first study to evaluate endodontic retreatment in mesial roots by CLSM.

According to some authors, ${ }^{5,13}$ the use of solvents may promote better dissolution of root canal filling material, facilitating the penetration of instruments into the root canal filling. However, this softening of filling material forms a film that may be easily compressed not only inside the irregularities of the canal walls, but also inside the dentinal tubules, thereby obliterating them. ${ }^{7,31}$ This effect compromises the cleaning of the root walls and delays the removal stage. In addition, other studies ${ }^{32,33}$ have demonstrated that the use of a solvent decreases the bond strength of endodontic sealers, a consequence which may compromise successful retreatment. Some studies ${ }^{31,34}$ recommend avoiding the use of solvents, and using only auxiliary chemical substances during removal of filling material. In our study, the use of orange oil did not improve the cleaning of the root walls, thereby showing no advantages for its use in clinical practice.

Sealer penetration inside the dentinal tubule is essential for filling a new root canal adequately. The current study demonstrated that the sealer was able to penetrate inside the dentinal tubules after retreatment, regardless of the residual filling, leading to an overlapping of the residual sealer with the new filling; in some cases, this resulted in a yellow coloration, similar to that observed by Rached-Júnior et al. ${ }^{14}$ In contrast, Kok et al. ${ }^{15}$ observed that the sealer of the new filling did not penetrate the dentinal tubules. Although this discrepancy in results can be explained by anatomical differences in the roots used in our study, the diameter of mesial mandibular roots is thinner, thus allowing greater contact of instruments with the root walls, and consequently more viable sealer penetration into dentinal tubules.

One major limitation of the present study was that only the ProTaper Retreatment system was used during root canal retreatment. Currently, new instruments with remarkable modifications in design (e.g. off-centered design, "snake-shaped design") and activation mode (e.g. reciprocating kinematics), in addition to the introduction of new thermally treated NiTi alloys (e.g. M-Wire, CM Wire, Blue Wire, Gold Wire), could lead to improved root canal filling materials. Future studies should be performed with these new instruments and technologies.

Based on the present results, it can be concluded that none of the retreatment protocols used was capable of fully eliminating the remnants of the first obturation from the canal walls. The use of solvents did not improve cleansing of the walls. PUI decreased the percentage of residual filling in the canal area. The isthmus proved to be an area critical to the cleaning and removal of filling material, but further studies must be performed with different protocols to achieve improved cleansing of this area after retreatment. 
Evaluation of the efficacy of filling material removal and re-filling after different retreatment procedures

\section{References}

1. Siqueira JF Jr, Rôças IN, Ricucci D, Hülsmann M.

Causes and management of post-treatment apical periodontitis. Br Dent J. 2014 Mar;216(6):305-12. https://doi.org/10.1038/sj.bdj.2014.200

2. Rossi-Fedele G, Ahmed HM. Assessment of root canal filling removal effectiveness using micro-computed tomography: A systematic review. J Endod. 2017 Apr;43(4):520-6. https://doi.org/10.1016/i.joen.2016.12.008

3. Rödig T, Reicherts P, Konietschke F, Dullin C, Hahn W, Hülsmann M. Efficacy of reciprocating and rotary $\mathrm{NiTi}$ instruments for retreatment of curved root canals assessed by micro-CT. Int Endod J. 2014 Oct;47(10):942-8. https://doi.org/10.1111/iej.12239

4. Zuolo AS, Mello JE Jr, Cunha RS, Zuolo ML, Bueno CE. Efficacy of reciprocating and rotary techniques for removing filling material during root canal retreatment. Int Endod J. 2013 Oct;46(10):947-53. https://doi.org/10.1111/iej.12085

5. Silva EJ, Orlowsky NB, Herrera DR, Machado R, Krebs RL, Coutinho-Filho TS. Effectiveness of rotatory and reciprocating movements in root canal filling material removal. Braz Oral Res. 2015;29:1-6.

6. Alves FR, Marceliano-Alves MF, Sousa JC, Silveira SB, Provenzano JC, Siqueira Junior JF. Removal of root canal filling in curved canals using either reciprocating single- or rotary multi-instruments systems and a supplementary step with the XP-Endo Finisher. J Endod. 2016 Jul;42(7):1114-9. https://doi.org/10.1016/j.joen.2016.04.007

7. Kfir A, Tsesis I, Yakirevich E, Matalon S, Abramovitz I. The efficacy of five techniques for removing root filling material: microscopic versus radiographic evaluation. Int Endod J. 2012 Jan;45(1):35-41. https://doi.org/10.1111/j.1365-2591.2011.01944.x

8. Alves FR, Ribeiro TO, Moreno JO, Lopes HP. Comparison of the efficacy of nickel-titanium rotary systems with or without the retreatment instruments in the removal of gutta-percha in the apical third. BMC Oral Health. 2014 Aug;14(1):102-6. https://doi.org/10.1186/1472-6831-14-102

9. Duarte MA, Só MV, Cimadon VB, Zucatto C, VierPelisser FV, Kuga MC. Effectiveness of rotary or manual techniques for removing a 6-year-old filling material. Braz Dent J. 2010;21(2):148-52. https://doi.org/10.1590/S0103-64402010000200010

10. Bernardes RA, Duarte MA, Vivan RR, Alcalde MP, Vasconcelos BC, Bramante CM. Comparison of three retreatment techniques with ultrasonic activation in flattened canals using micro-computed tomography and scanning electron microscopy. Int Endod J. 2016 Sep;49(9):890-7. https://doi.org/10.1111/iej.12522

11. Akbulut MB, Akman M, Terlemez A, Magat G, Sener $\mathrm{S}$, Shetty H. Efficacy of Twisted File Adaptive, Reciproc and ProTaper Universal Retreatment instruments for root-canal-filling removal: A cone-beam computed tomography study. Dent Mater J. 2016;35(1):126-31. https://doi.org/10.4012/dmi.2015-214

12. Da Rosa RA, Santini MF, Cavenago BC, Pereira JR, Duarte MA, Só MV. Micro-CT Evaluation of Root Filling Removal after Three Stages of Retreatment Procedure. Braz Dent J. 2015 Nov-Dec;26(6):612-8. https://doi.org/10.1590/0103-6440201300061

13. Sağlam BC, Koçak MM, Türker SA, Koçak S. Efficacy of different solvents in removing gutta-percha from curved root canals: a micro-computed tomography study. Aust Endod J. 2014 Aug;40(2):76-80. https://doi.org/10.1111/aej.12041

14. Rached-Júnior FA, Sousa-Neto MD, Bruniera JF, Duarte MA, Silva-Sousa YT. Confocal microscopy assessment of filling material remaining on root canal walls after retreatment. Int Endod J. 2014;47(3):264-70. https://doi.org/10.1111/iej.12142.

15. Kok D, Rosa RA, Barreto MS, Busanello FH, Santini MF, Pereira JR et al. Penetrability of AH plus and MTA fillapex after endodontic treatment and retreatment: a confocal laser scanning microscopy study. Microsc Res Tech. 2014 Jun;77(6):467-71. https://doi.org/10.1002/jemt.22371

16. Kim H, Kim E, Lee SJ, Shin SJ. Comparisons of the retreatment efficacy of calcium silicate and epoxy resin-based sealers and residual sealer in dentinal tubules. J Endod. 2015 Dec;41(12):2025-30. https://doi.org/10.1016/i.joen.2015.08.030

17. Estrela C, Rabelo LE, Souza JB, Alencar AH, Estrela CR, Sousa Neto MD et al. Frequency of Root Canal Isthmi in Human Permanent Teeth Determined by Cone-beam Computed Tomography. J Endod. 2015 Sep;41(9):1535-9. https://doi.org/10.1016/i.joen.2015.05.016

18. Leoni GB, Versiani MA, Silva-Sousa YT, Bruniera JF, Pécora $J D$, Sousa-Neto MD. Ex vivo evaluation of four final irrigation protocols on the removal of hard-tissue debris from the mesial root canal system of mandibular first molars. Int Endod J. 2017 Apr;50(4):398-406. https://doi.org/10.1111/iej.12630

19. Lima FJ, Montagner F, Jacinto RC, Ambrosano GM, Gomes BP. An in vitro assessment of type, position and incidence of isthmus in human permanent molars. J Appl Oral Sci. 2014 Jul-Aug;22(4):274-81. https://doi.org/10.1590/1678-775720130585

20. Mehrvarzfar P, Akhlagi NM, Khodaei F, Shojaee G, Shirazi $S$. Evaluation of isthmus prevalence, location, and types in mesial roots of mandibular molars in the Iranian Population. Dent Res J (Isfahan). 2014 Mar;11(2):251-6.

21. Schneider SW. A comparison of canal preparations in straight and curved root canals. Oral Surg Oral Med Oral Pathol. 1971 Aug;32(2):271-5. https://doi.org/10.1016/0030-4220(71)90230-1 
22. Estrela C, Holland R, Estrela CR, Alencar AH, SousaNeto MD, Pécora JD. Characterization of successful root canal treatment. Braz Dent J. 2014 Jan-Feb;25(1):3-11. https://doi.org/10.1590/0103-6440201302356

23. Kara Tuncer $A$, Tuncer $S$. Effect of different final irrigation solutions on dentinal tubule penetration depth and percentage of root canal sealer. J Endod. 2012 Jun;38(6):860-3. https://doi.org/10.1016/j.joen.2012.03.008

24. De-Deus G, Brandão MC, Leal F, Reis C, Souza EM, Luna AS et al. Lack of correlation between sealer penetration into dentinal tubules and sealability in nonbonded root fillings. Int Endod J. 2012 Jul;45(7):642-51. https://doi.org/10.1111/j.1365-2591.2012.02023.x

25. Shenoy A, Ahmaduddin, Bolla N, Raj S, Mandava P, Nayak S. Effect of final irrigating solution on smear layer removal and penetrability of the root canal sealer. J Conserv Dent. 2014 Jan;17(1):40-4. https://doi.org/10.4103/0972-0707.124132

26. Pécora JD, Estrela C, Bueno MR, Porto OC, Alencar $A H$, Sousa-Neto MD et al.. Detection of root canal isthmuses in molars by map-reading dynamic using CBCT images. Braz Dent J. 2013;24(6):569-74. https://doi.org/10.1590/0103-6440201302380

27. Gu LS, Ling JQ, Wei X, Huang XY. Efficacy of ProTaper Universal rotary retreatment system for gutta-percha removal from root canals. Int Endod J. 2008 Apr;41(4):288-95. https://doi.org/10.1111/j.1365-2591.2007.01350.x

28. Ma J, Al-Ashaw AJ, Shen Y, Gao Y, Yang Y, Zhang C et al. Efficacy of ProTaper Universal Rotary Retreatment system for gutta-percha removal from oval root canals: a microcomputed tomography study. J Endod. 2012 Nov;38(11):1516-20. https://doi.org/10.1016/i.joen.2012.08.001
29. Barreto MS, Rosa RA, Santini MF, Cavenago BC, Duarte $M A$, Bier CA et al. Efficacy of ultrasonic activation of $\mathrm{NaOCl}$ and orange oil in removing filling material from mesial canals of mandibular molars with and without isthmus. J Appl Oral Sci. 2016 Jan-Feb;24(1):37-44. https://doi.org/10.1590/1678-775720150090

30. Cavenago BC, Ordinola-Zapata R, Duarte MA, del CarpioPerochena AE, Villas-Bôas MH, Marciano MA et al. Efficacy of xylene and passive ultrasonic irrigation on remaining root filling material during retreatment of anatomically complex teeth. Int Endod J. 2014 Nov; 47(11):1078-83. https://doi.org/10.1111/iej.12253

31. Horvath SD, Altenburger MJ, Naumann M, Wolkewitz $M$, Schirrmeister JF. Cleanliness of dentinal tubules following gutta-percha removal with and without solvents: a scanning electron microscopic study. Int Endod J. 2009 Nov;42(11):1032-8. https://doi.org/10.1111/j.1365-2591.2009.01616.x

32. Topçuoğlu HS, Demirbuga S, Tuncay Ö, Arslan H, Kesim $B$, Yaşa B. The bond strength of endodontic sealers to root dentine exposed to different gutta-percha solvents. Int Endod J. 2014;47(12):1100-6. https://doi.org/10.1111/iej.12257.

33. Palhais M, Sousa-Neto MD, Rached-Junior FJ, Amaral MC, Alfredo E, Miranda CE et al. Influence of solvents on the bond strength of resin sealer to intraradicular dentin after retreatment. Braz Oral Res. 2017 Jan;31(0):e11. https://doi.org/10.1590/1807-3107bor-2017.vol31.0011

34. Martos J, Silveira LF, Silveira CF, Castro LA, Ferrer-Luque CM. The effect of different organic solvents on the degradation of restorative materials. Eur J Dent. 2013 Jul;7(3):347-51. https://doi.org/10.4103/1305-7456.115419 